17. Richter M. Pimp my ride for 2010: Sex work, legal reform and HIV/AIDS. Gender \& Media Diversity Journal 2009; 7: 80-88

18. Loff B, Gaze B, Fairley C. Prostitution, public health, and human-rights law. Lancet 2000; 356: 1764
19. Richter M, Massawe D. A report on the consultation on HIV/AIDS, sex work and the 2010 Soccer World Cup - human rights, public health, soccer and beyond. South African National A Court holel, Cape Town, $26-27$ November 2009. http// www sweto consult $\% 20$ meet $\% 20$ report $\% 20$ web\%20singles2.pdf (accessed 10 March 2010).

\title{
Rugby and cervical spine injuries
}

At the time of writing, a Cape newspaper reported on a 21-year-old rugby player who died on the field following a presumed spine injury. This highlights the ongoing concerns regarding safety in this contact sport. Although the physicality of rugby is a large part of its attraction, both to spectators and players, no one wishes serious harm.

Two papers in this issue of $S A M J$ review rugby-related injuries to the spine and spinal cord.

Hermanus et al. ${ }^{1}$ provide a 27 -year epidemiological review of the national occurrence of rugby-related spinal cord injuries (SCIs). Under the guidance of Professor Noakes of the Sports Science Institute, the authors identified 264 SCIs. Sadly, 25\% of these patients had died since sustaining the injury. Data were collected on 183 patients (including 30 deceased).

Dunn $e t$ al. ${ }^{2}$ looked at the issue from the perspective of a Western Cape regional acute spine injury unit, reviewing 27 admissions over a 5-year period. This cohort had spinal column injuries, with 6 of the cohort presenting with normal neurological function but mechanical instability requiring stabilisation.

The Hermanus study found an increasing number of injuries up to 2005, with a slight reduction to 12 in 2007. This in contrast to the New Zealand experience of reduced annual injury rates over the past few years. ${ }^{3}$ Dunn et al. found that the Western Cape injury incidence was reduced compared with that in reports from the 1980s, with a current injury rate of 5.4 per annum and a catastrophic injury rate of 1.8 per annum. Of course, any spine injury is one too many.

Both studies found the tackle to be the commonest phase of play in which injury is sustained. This may well be due to recent rule changes reducing scrums by as much as $40 \%$ per game.

Hermanus et al. found a higher incidence of injuries in forwards, with Dunn et al. reporting equal rates in forwards versus the backline. This may well be attributable to the periods reviewed, with the changing game and increasing tackling injury risk increasing backline injuries in the latter years.

The high rate of hooker injuries $30 \%$ in the Hermanus study) confirms the long-held view in terms of risk in this playing position, yet in the recent 5-year period this is no longer the case in the Western Cape, as hookers only account for $11 \%$ of the injuries and scrumhalves and props lead the injury table.

Dunn et al. identified games played outside the metropole as high risk. It is postulated that this represents more poorly controlled games, with immature players playing in higher leagues because of small numbers in the clubs. Hermanus et al. note that there is a demographic bias to access to medical resources and subsequent outcome. Concerns regarding foul play are also raised, with $30 \%$ of injuries occurring as a result of this.

Access to appropriate medical care is a problem highlighted in both papers. Hermanus et al. state that on-site medical personnel were only available in $50 \%$ of cases, with the injured player not being appropriately immobilised in a third of cases. The first medical contact point was frequently inadequate, requiring transfer. This correlated with poorer outcomes.

The vast majority of spinal injuries were dislocations. Dunn et al. followed their cohort up in terms of neurological outcome. None of the ASIA As (complete motor and sensory function) on admission recovered. In contrast to this, 2 of the Bs (sensory preservation) improved to normal. This finding highlights the importance of early recognition of any neurological preservation and appropriate intervention. All the Ds (minor impairment) improved to normal and no surviving patient deteriorated neurologically.

Both studies highlight the difficulty in providing an injury incidence, as surprisingly the number of players/games is not known. Hermanus et al. make a plea to establish a prospective injury register.

Dunn et al. note that only a few injured players (19\%) considered SCI a possibility before injury, and that despite their predicament $60 \%$ would still recommend that their sons play the game. This highlights the strong commitment to the game and the need to make it safer.

Both these studies have provided the impetus for SA Rugby to embark on a proactive educational programme. BokSmart is educating all role players in an effort to minimise injury and promote safe play.

\section{Robert Neil Dunn}

Department of Orthopaedic Surgery University of Cape Town

Corresponding author: R N Dunn (robdunn@mweb.co.za)

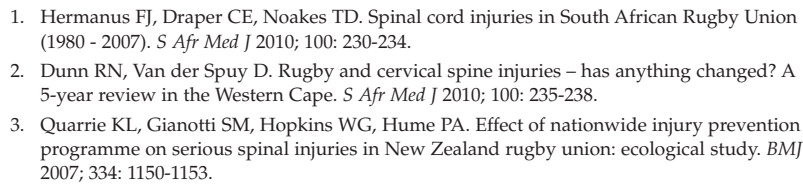

3. Quarrie KL, Gianotti SM, Hopkins WG, Hume PA. Effect of nationwide injury prevention programme on serious spinal injuries in New Zealand rugby union: ecological study. $B M$ 2007; 334: 1150-1153. 